Keyhole behaviour during laser welding of zinc-coated steel

This article has been downloaded from IOPscience. Please scroll down to see the full text article.

2011 J. Phys. D: Appl. Phys. 44045502

(http://iopscience.iop.org/0022-3727/44/4/045502)

View the table of contents for this issue, or go to the journal homepage for more

Download details:

IP Address: 131.180.130.109

The article was downloaded on 10/05/2012 at 14:16

Please note that terms and conditions apply. 


\title{
Keyhole behaviour during laser welding of zinc-coated steel
}

\author{
Y Pan ${ }^{1}$ and I M Richardson ${ }^{1,2}$ \\ ${ }^{1}$ Material Innovation Institute, Mekelweg 2, 2628 CD Delft, The Netherlands \\ 2 Department of Materials Science and Technology, Delft University of Technology, Mekelweg 2, \\ 2628 CD Delft, The Netherlands \\ E-mail: y.pan@m2i.nl and i.m.richardson@tudelft.nl
}

Received 28 July 2010, in final form 18 November 2010

Published 11 January 2011

Online at stacks.iop.org/JPhysD/44/045502

\begin{abstract}
The production of consistent, high-quality laser welds on zinc-coated steels for the automotive industry remains a challenge. A simple overlap joint geometry is desirable in these applications but has been shown to be extremely detrimental to laser welding because the zinc vapour formed at the interface between the two sheets expands into the keyhole and disrupts fluid flow in the melt pool, which often leads to metal ejection. In this work, laser welding on sheets with various coating thicknesses has been performed and it is observed that the sheets with thick coatings $(\sim 20 \mu \mathrm{m})$ show surprisingly good weldability. High speed video camera visualizations of the keyhole provide insight into the keyhole dynamics during the process. It appears that the dynamic pressure of zinc vapour can effectively elongate the keyhole and the process can reach a stable state when an elongated keyhole is continuously present. A simple analytical model has been developed to describe the influence of zinc vapour on keyhole elongation.
\end{abstract}

(Some figures in this article are in colour only in the electronic version)

\section{Introduction}

Laser welding of zinc-coated steel sheets in an overlap joint configuration is commonly used in the automotive industry. A major problem that arises when welding these materials is associated with the vaporization temperature of zinc $\left(906^{\circ} \mathrm{C}\right)$, which is much lower than the melting temperature of steel $\left(1530^{\circ} \mathrm{C}\right)$. In an overlap configuration, the zinc vapour produced between the sheets during welding will vent through the keyhole, particularly when no gap is present between the overlapping sheets. This causes unstable fluid flow and molten metal is often ejected from the pool, resulting in the formation of pores and severe undercut.

One of the first methods introduced and still in use today to overcome this problem is to set a gap between the sheets prior to the welding, usually in the range $0.1-0.2 \mathrm{~mm}$, which provides a channel for the escape of the zinc vapour [1-4]. However, this solution can be undesirable because of the difficulty associated with maintaining such gaps in industrial configurations. Another possibility involves enlarging the keyhole in order to facilitate the escape of zinc vapour, by using elongated or dual focus laser spots $[4,5]$. This method can minimize the destabilizing influence of zinc vapour on the melt pool; how- ever, it requires careful control of the laser power distribution. Reduced power intensity on the material surface and hence reduced productivity limit the attractiveness of this method.

Previously, it was reported that welding of zinc-coated sheets without any special arrangements can be successfully performed under certain circumstances [6-8]. In this work, the weldability of materials with two different coating thicknesses has been studied. High-speed camera visualization techniques have been employed to explore dynamic changes in keyhole dimensions. It is found that while some sheets with a $7 \mu \mathrm{m}$ zinc coating thickness are difficult to weld with zero gap, others with a $20 \mu \mathrm{m}$ zinc coating thickness, which might be expected to exacerbate process instability, show good weldability. This surprising result is associated with keyhole shape and dynamic variations. An analysis of keyhole evolution is presented for both stable and unstable cases and possible reasons for the observed behaviour are considered. A simple analytical model is suggested relating operating parameters (welding speed) and material properties (coating thickness, surface tension and density) to describe the influence of zinc vapour on keyhole geometry. 
Table 1. Composition of the base steel in wt $\%$.

\begin{tabular}{llllllllllll}
\hline Element & $\mathrm{Al}$ & $\mathrm{C}$ & $\mathrm{Cr}$ & $\mathrm{Cu}$ & $\mathrm{Mn}$ & $\mathrm{Ni}$ & $\mathrm{P}$ & $\mathrm{S}$ & $\mathrm{Si}$ & $\mathrm{Ti}$ & $\mathrm{Fe}$ \\
\hline $\mathrm{wt} \%$ & 0.026 & $<0.001$ & 0.018 & 0.016 & 0.104 & 0.053 & 0.012 & 0.005 & 0.001 & 0.030 & Bal. \\
\hline
\end{tabular}

\section{Background}

The stability of a weld pool is governed by a number of factors. Surface tension plays a significant role in retaining the weld pool, and is a complex function of temperature [9], pool geometry and surface chemistry [10]; all of which may vary with time and position. Temperature is determined by the balance of heat input and heat losses and shows strong spatial variation in fusion welding processes. During laser welding the surface tension distribution is dependent on the laser beam power and the power density, which influence pool size and surface temperature distribution as well as pool chemistry (through vaporization).

High-power density laser beams, for example, can create local evaporation, and the reaction forces generated at the pool surface give rise to keyhole opening. The dynamic behaviour of the keyhole is decisive for the welding process. Keyhole fluctuations, particularly parallel to the welding direction, can stimulate weld pool oscillations. Conversely, large oscillation amplitudes of the melt pool may lead to a collapse of the keyhole and result in weld seam defects such as porosity and undercut $[11,12]$. To keep the keyhole open, the energy balance and the pressure balance at the keyhole wall must be satisfied [13]. The metal vapour inside the keyhole acts against the surface tension to keep the keyhole open $[13,14]$.

Inside the melt pool during a laser welding process, different types of melt flow can take place, driven by buoyancy, surface tension gradients, surface drag due to impinging gas flows or vaporization $[15,16]$. The relative importance of the driving forces varies with operating conditions. Marangoni convection driven by surface tension gradients is dominant when welding at relatively low speeds $[17,18]$; however, it has been reported to be less dominant with increasing welding speed $[19,20]$ or when a side gas jet is applied [20,21]. Another major feature of the melt flow includes liquid transport around the keyhole [16,22]. The driving force for this motion is the evaporation recoil pressure at the front of the keyhole, controlled by the input laser power, power density and welding speed [16]. At lower welding speeds the melt pool between the keyhole and the melting isotherm is wide, resulting in a less constrained, low-speed flow. At high welding speeds, a much higher liquid metal flow speed is generated because the volume of metal melted per unit time increases and the melt pool between the leading edge of the keyhole and the melting isotherm becomes dense [23,24]. This melt flows around the keyhole, collides with the slowly moving weld pool and is forced upwards and downwards, forming a weld bead shape with a central peak and undercut at either side [16].

Fluid flow has a substantial influence on energy transport within a liquid weld pool, and changes in flow pattern may substantially alter the shape of the pool [25]. Changes in laser power, power density or pool size will have some influence on vaporization and the reaction forces generated at the weld pool surface.

When welding zinc-coated sheets in an overlap configuration, the influence that zinc vapour exerts on weld pool fluid flow and energy transport is strongly dependent on the flow geometry. During bead-on-plate welding or overlap welding with gaps of $0.1 \mathrm{~mm}$ between the sheets (such that zinc vapour can escape), zinc vapour has only a small influence on weld pool size and shape. Conversely, when stake welding with no gap between the sheets, vapour escape through the melt pool can lead to unacceptable instability [1-4]. During laser welding the amount of zinc vaporized per unit time is the product of the mean coating thickness, the welding speed and the width of the region where the surface temperature exceeds the vaporization temperature of the zinc layer. This in turn is influenced by the welding speed, the beam power and the surface power density as well as the material thickness and thermo-physical properties. The way in which the vapour impinges on the weld pool and the subsequent influence on both process stability and weld pool geometry are considered in this work.

\section{Experimental conditions}

This study was carried out using a Nd: YAG (wavelength $1064 \mathrm{~nm}$ ) laser with a nominal power of $3 \mathrm{~kW}$. The focal distance was $150 \mathrm{~mm}$, projecting the laser beam to a spot of $450 \mu \mathrm{m}$ diameter. The laser beam was focused on the top surface of the sheet with the beam perpendicular to the surface. No shielding or backing gases were used in the tests. All welds reported were made at a beam power of $3 \mathrm{~kW}$ and welding speeds were varied in the range $25-55 \mathrm{~mm} \mathrm{~s}^{-1}$.

Experiments were performed on $0.8 \mathrm{~mm}$ thick DX54D hot dip galvanized (GI) zinc-coated sheet steels with nominal zinc coating thicknesses of 7 and $20 \mu \mathrm{m}$. The chemical composition of the base steel is given in table 1. After welding, the specimens were checked visually and cross-sections were made. Visual weld quality was quantified by a length fraction, defined by the length of the weld seam without any pores or severe undercut divided by the total length of the seam. The average length fractions were determined for 3 welds of $100 \mathrm{~mm}$ length per parameter set.

The dynamic behaviour of the keyhole was filmed with a Phantom v5.0 CMOS camera at a sampling rate of $30000 \mathrm{fps}$. The camera was placed coaxially with the laser beam. The laser focusing lens provided an image of the top surface of the keyhole and melt pool, directed towards the camera by means of a dichroic mirror mounted inside the laser head, as shown in figure 1. Since the keyhole and vapour plume are well illuminated by process radiation, no external illumination was necessary.

Temperature measurements were performed with standard $0.13 \mathrm{~mm}$ diameter K-type thermocouples to determine the 


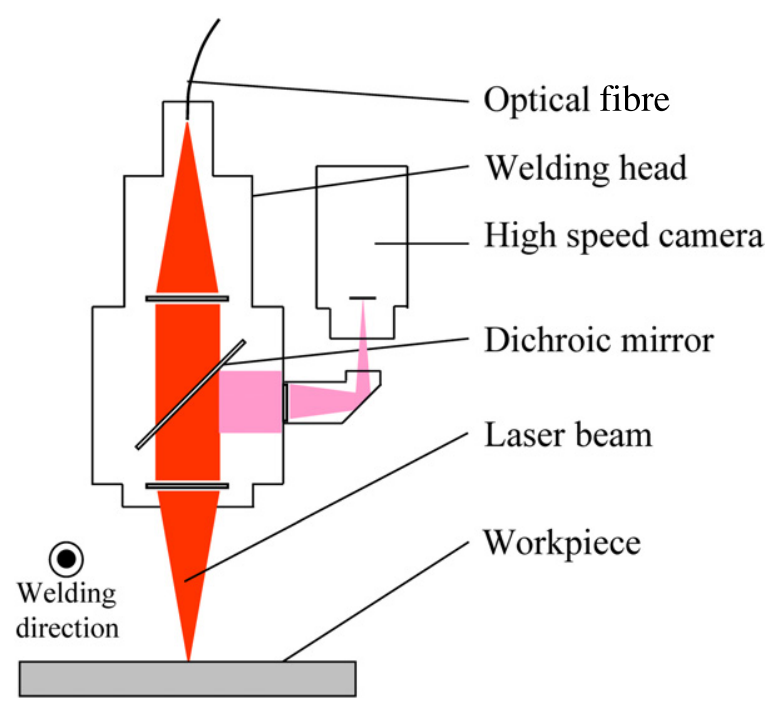

Figure 1. Experimental arrangement for high speed video visualization.

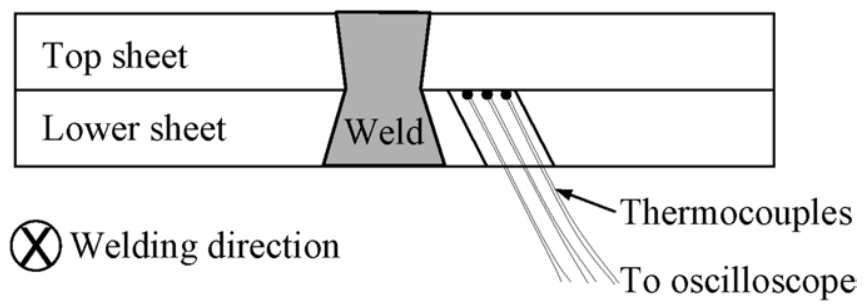

Figure 2. Temperature measurements at the interface between the two sheets.

position of the zinc boiling isotherm at the interface between the two sheets. The locations of the thermocouples are shown schematically in figure 2. Thermocouples were attached on the cleaned surface along a line perpendicular to the welding direction. Small pieces of ceramic were used to isolate the individual thermocouple wires. The exact positions were measured after welding to determine the position where the maximum temperature approached the zinc vaporization temperature of $1180 \mathrm{~K}$.

\section{Results}

Prior to welding, the coated sheets were sectioned to examine the original coating thickness and thickness variations. Measurements were performed at intervals of $1 \mathrm{~mm}$ along a $100 \mathrm{~mm}$ sample length. Results show an average thickness of $21.4 \mu \mathrm{m}$ for the $20 \mu \mathrm{m}$ nominal thick coating thickness, with a standard deviation of $\pm 1.6 \mu \mathrm{m}$, and an average thickness of $8.7 \mu \mathrm{m}$ for the $7 \mu \mathrm{m}$ nominal coating thickness with a standard deviation of $\pm 2.2 \mu \mathrm{m}$ (figure 3 ).

The weld quality, quantified by the length fraction, is shown in figure 4 . As expected the presence of the zinc coating reduces the weld quality. It is notable that better quality welds were obtained for the $20 \mu \mathrm{m}$ coating thickness GI sheets, while the welds on steels with a $7 \mu \mathrm{m}$ coating thickness showed a significant number of defects. It is also found that better quality is obtained at lower welding speeds.

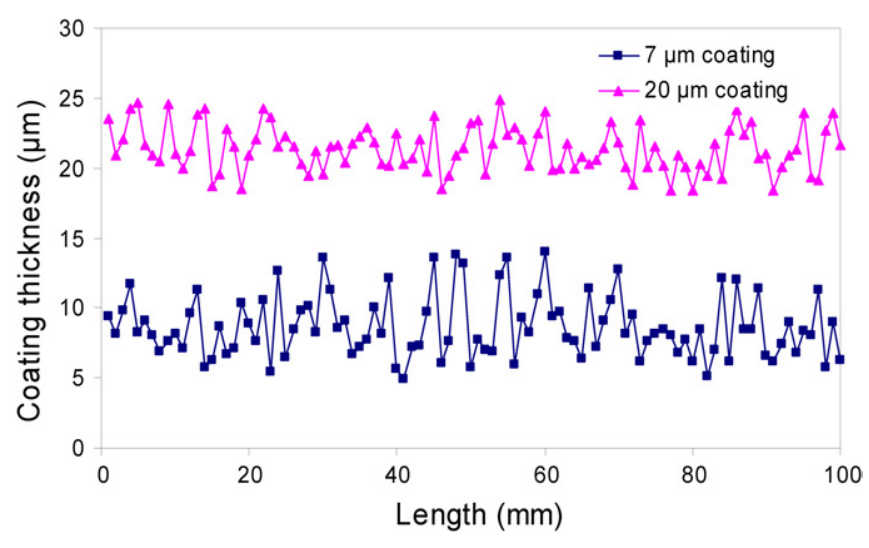

Figure 3. Coating thickness variation of two GI coated steels.

Typical transverse cross-sections of welds are shown in figure 5 . It can be seen that weld quality is relatively good, with uniform zinc layers adjacent to the weld at the steel interface for the $20 \mu \mathrm{m}$ coating thickness (figure 5(a)), which is in agreement with previously published results [26]. In contrast, a poor quality weld is found in the case of the $7 \mu \mathrm{m}$ coating thickness, as shown in figure 5(b). Large pores are found in the fusion zone, some of which are filled with zinc, indicating that these pores connect with the sheet interface and that liquid zinc can flow during weld solidification. It is also found that there is only a very irregular appearance of zinc adjacent to the weld at the interface. According to the visual inspection and element mapping, no zinc is found in the weld zone [27]; this indicates that zinc diffusion into the weld pool is negligibly small and that almost all the zinc that is vaporized escapes through the keyhole.

Weld end craters were sectioned longitudinally to examine the zinc distribution in front of the keyhole and results are shown in figure 6. In figure 6(a), it can be seen that the liquid steel on the keyhole front wall is completely penetrated by the zinc vapour, and liquid zinc has flown through the resulting channel during solidification. In contrast, in figure $6(b)$ a separation region appears at the fusion boundary without penetrating into the keyhole. In this case liquid zinc is found to flow between the solid steel surface and the prior liquid steel melt pool.

Based on coaxial views of the keyhole opening for zinc coated and non-coated steels (figure 7), the keyhole geometry can be approximately reconstructed with respect to the inclination of the keyhole front wall and the shape of the keyhole top aperture. The grey scale indicates a combination of both laser and radiative intensities. The bright zone on the images indicates the material directly exposed to the laser beam. The dark area in the centre of keyhole indicates that the steel sheets have been fully penetrated. Here the laser beam travels through the keyhole without any laser-material interaction. It is found that the keyhole widths are virtually constant, being defined by the incident focal spot dimensions. In contrast, the keyhole length increases when welding zinccoated sheets, and a channel for zinc vapour evacuation forms. This corresponds to the dark line in the middle of the keyhole front wall, which indicates that the zinc vapour penetrates the liquid film at this location and escapes into the keyhole. This 


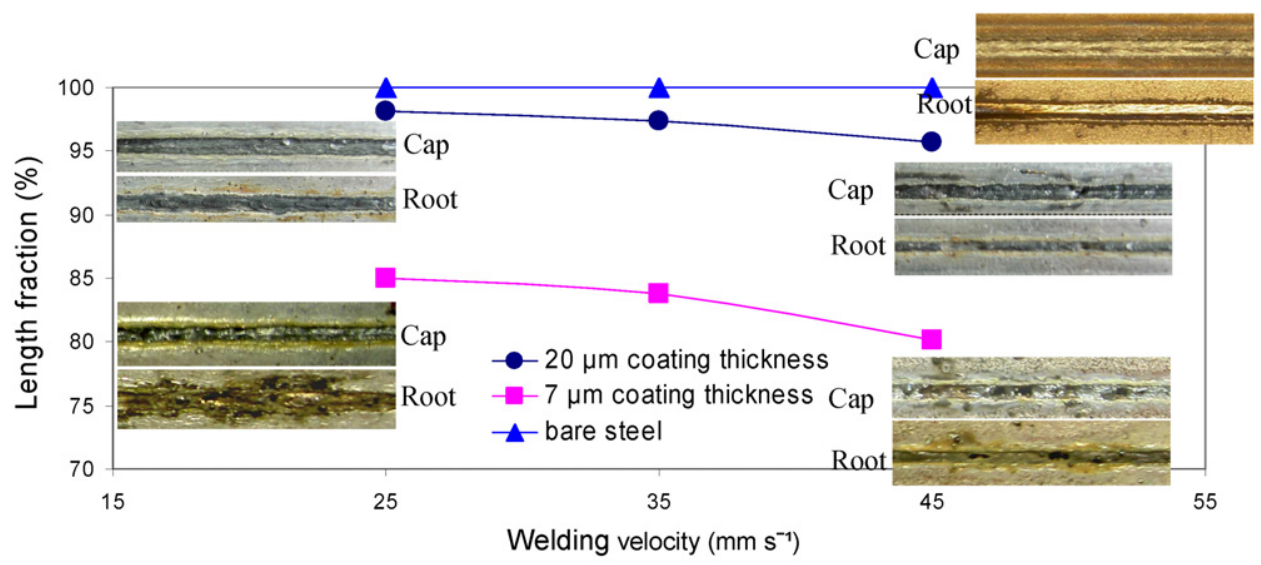

Figure 4. Fraction of acceptable weld for weld beads on $20 \mu \mathrm{m}$ and $7 \mu \mathrm{m}$ zinc coating thickness GI sheets and non-coated steel. Photographs show the cap and the root of the seams.
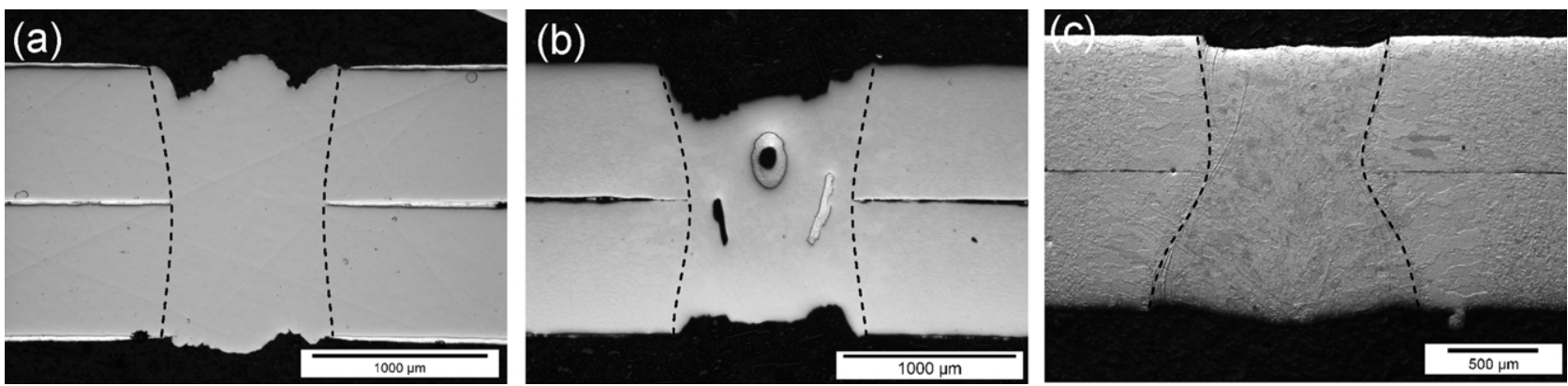

Figure 5. Traverse cross-sections of welds made on $(a) 20 \mu \mathrm{m},(b) 7 \mu \mathrm{m}$ coating thickness coated sheets, and $(c)$ bare steel with a laser power of $3 \mathrm{~kW}$ and travel speed of $45 \mathrm{~mm} \mathrm{~s}^{-1}$.

elongation effect is readily apparent in the case of the $20 \mu \mathrm{m}$ zinc coating thickness (figure 7 , images on the right).

During welding of bare steels, a characteristically sloping rear keyhole wall is expected as a consequence of laser beam reflection from the front wall [7]. This is evident in the photographs in the left column of figure 7 . However, relatively straight rear walls are observed when welding zinc-coated steels.

\section{Discussion}

\subsection{Zinc vapour evacuation through the keyhole front wall}

In the numerical simulation presented by Geiger et al [28] it was shown that as the gap at the interface between two uncoated sheets welded in an overlap configuration increases to $0.05-0.1 \mathrm{~mm}$, the liquid metal on the keyhole front wall tends to separate; i.e. a channel opens connecting the interface gap to the keyhole. It is reasonable to expect that this will occur at smaller gaps when a pressure gradient exists between the interface and the keyhole, caused, for example, by the evolution of zinc vapour.

It is shown in figure 3 that the thickness of the $20 \mu \mathrm{m}$ coating is more uniform than that of the $7 \mu \mathrm{m}$ coating. A more consistent supply of zinc vapour into the keyhole can be expected when welding the sheets with the thicker zinc coating. With a thick coating, as shown in figures 5(a) and $(b)$, a more consistent zinc vapour evacuation channel will open,

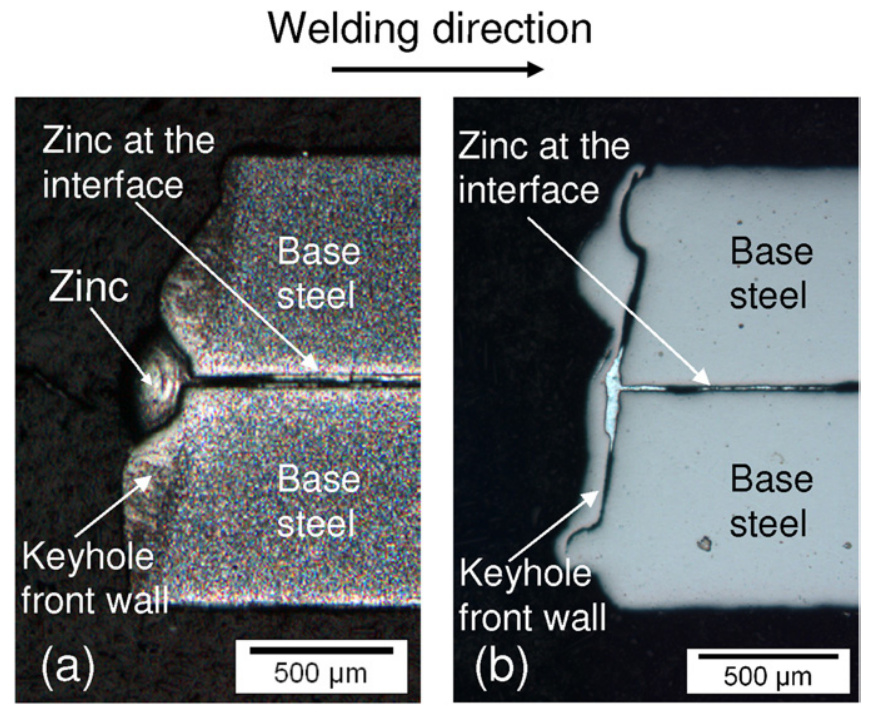

Figure 6. Longitudinal cross-sections of weld end craters showing (a) zinc flow into the keyhole (etched with $2 \%$ saturated nitric acid solution for $4 \mathrm{~s}$ ) and (b) zinc trapped behind the keyhole wall (not etched). Processing power and speeds are $3 \mathrm{~kW}$ and $45 \mathrm{~mm} \mathrm{~s}^{-1}$.

partly because of the constant zinc vapour pressure but also because a larger gap already exists after the vaporization of the $40 \mu \mathrm{m}$ zinc coating at the interface. The visible presence of zinc vapour evacuation channels, as shown in figure 7, was analysed to give the percentage of images showing the channel. 
Bare steel
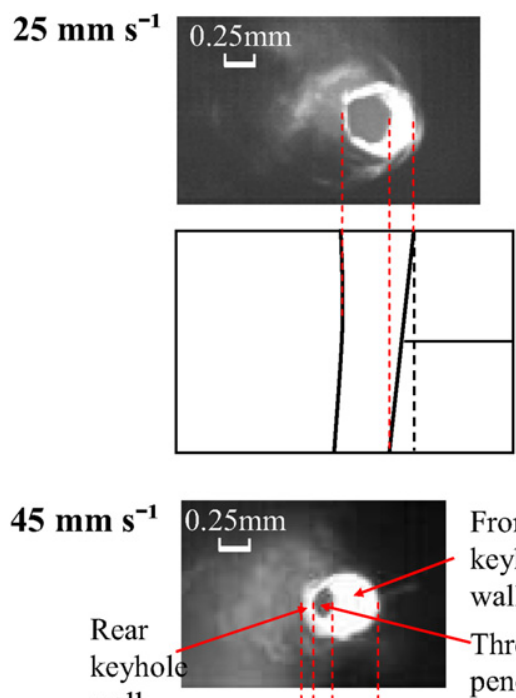

wall

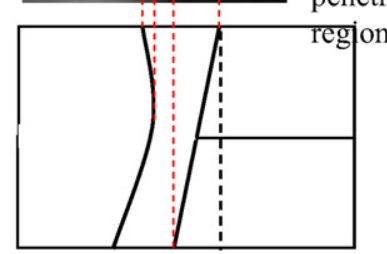

$7 \mu \mathrm{m}$ coating thickness
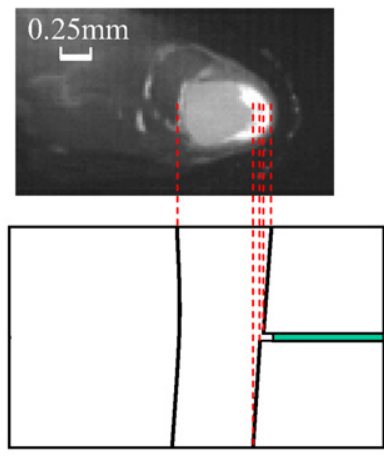

$\rightarrow$ Keyhole length
$20 \mu \mathrm{m}$ coating thickness
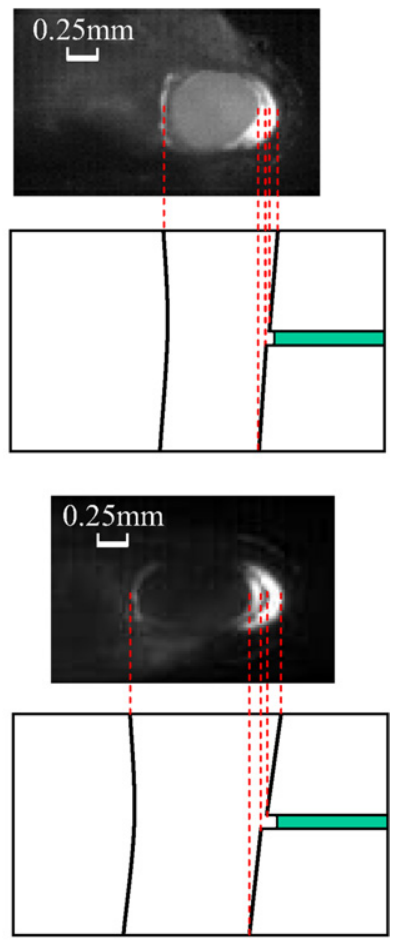

Welding direction

Figure 7. Welding of non-coated and zinc-coated steels at welding speeds of $(a) 45$ and $(b) 25 \mathrm{~mm} \mathrm{~s}^{-1}$. The first rows in each case show coaxial views of the keyhole at the top surface and the second rows show schematic keyhole profiles (laser power: $3 \mathrm{~kW}$ ).

For the $20 \mu \mathrm{m}$ coating thickness, $94.6 \%$ show the presence of a channel at a welding speed of $25 \mathrm{~mm} \mathrm{~s}^{-1}$ and $92 \%$ at $45 \mathrm{~mm} \mathrm{~s}^{-1}$, compared with $63.9 \%$ and $61.0 \%$ for the $7 \mu \mathrm{m}$ coating thickness.

\subsection{Keyhole elongation behaviour during welding}

The keyholes with modified shapes shown in figure 7 are similar to those reported by Fabbro et al [7] and Schmidt [29], which show that the keyhole shape is strongly influenced by the dynamic pressure of the zinc vapour. In order to develop a statistical evaluation of the keyhole geometry, a continuous video sequence of 10240 images (representing a time period of $0.34 \mathrm{~s}$ ) for steady-state welding was analysed for each parameter combination. The sequence was divided into 10 bins (groups) of consecutive images, each of them comprising 1024 images. Average keyhole lengths were calculated in each bin and the evolution of keyhole lengths is shown in figure 8 . When welding at $25 \mathrm{~mm} \mathrm{~s}^{-1}$, the keyhole is elongated to about $0.93 \mathrm{~mm}(20 \mu \mathrm{m}$ coating thickness) from $0.56 \mathrm{~mm}$ (bare steel). This effect is more significant when welding at $45 \mathrm{~mm} \mathrm{~s}^{-1}$, ranging from $0.58 \mathrm{~mm}$ for bare steel to $1.34 \mathrm{~mm}$ for the steel with $20 \mu \mathrm{m}$ thick zinc coating. It was reported that the inclination angle of the keyhole front wall increases with increasing welding speed, resulting in reduced direct transmission of the beam through the keyhole and increased beam absorption, due both to an increased exposure area and multiple reflections within the keyhole [20,30,31]. Fabbro et al [30] report that for a $1 \mathrm{~mm}$ thick steel sheet, increasing welding speed above $7 \mathrm{~m} \mathrm{~min}^{-1}\left(117 \mathrm{~mm} \mathrm{~s}^{-1}\right)$, until no direct beam transmission through the keyhole occurs, results in an elongated keyhole due to the plume emitted from the keyhole front wall and the influence of laser beam reflections. However, the range of welding speeds examined here $\left(25-55 \mathrm{~mm} \mathrm{~s}^{-1}\right)$ is much lower than the speed reported to lead to an elongated keyhole and this behaviour does not explain the longer keyhole obtained when welding zinc-coated sheets.

Observation of constant keyhole widths for all of the welding cases studied (as shown in figure 7) suggests that approximately uniform zinc vaporization isotherms will arise ahead of the keyhole, independent of the coating thickness. This indicates that a higher mass flow rate is required to evacuate the zinc vapour in the case of the thicker coating. Hence a higher vapour dynamic pressure at a given position in the keyhole can be expected, which explains the longer keyhole obtained with the $20 \mu \mathrm{m}$ coating. For a given coating thickness, it is observed that when the welding speed increases from 25 to $45 \mathrm{~mm} \mathrm{~s}^{-1}$ (a factor of 1.8), the cross-sectional area decreases. For the $20 \mu \mathrm{m}$ coating thickness, for example, the area decreases by a factor of 1.1. Since parallel sided weld profiles are obtained (as shown in figure 5), the width of the weld waist also decreases by a factor of 1.1. Assuming that the zinc in the weld area is vaporized and leaves through the keyhole, the volume of the vapour expanding into the keyhole per unit time increases by a factor of 1.6 when increasing welding speed from 25 to $45 \mathrm{~mm} \mathrm{~s}^{-1}$. Thus a higher mass flow rate is produced when welding at the higher welding speed, leading to a higher vapour pressure at a given position in the 

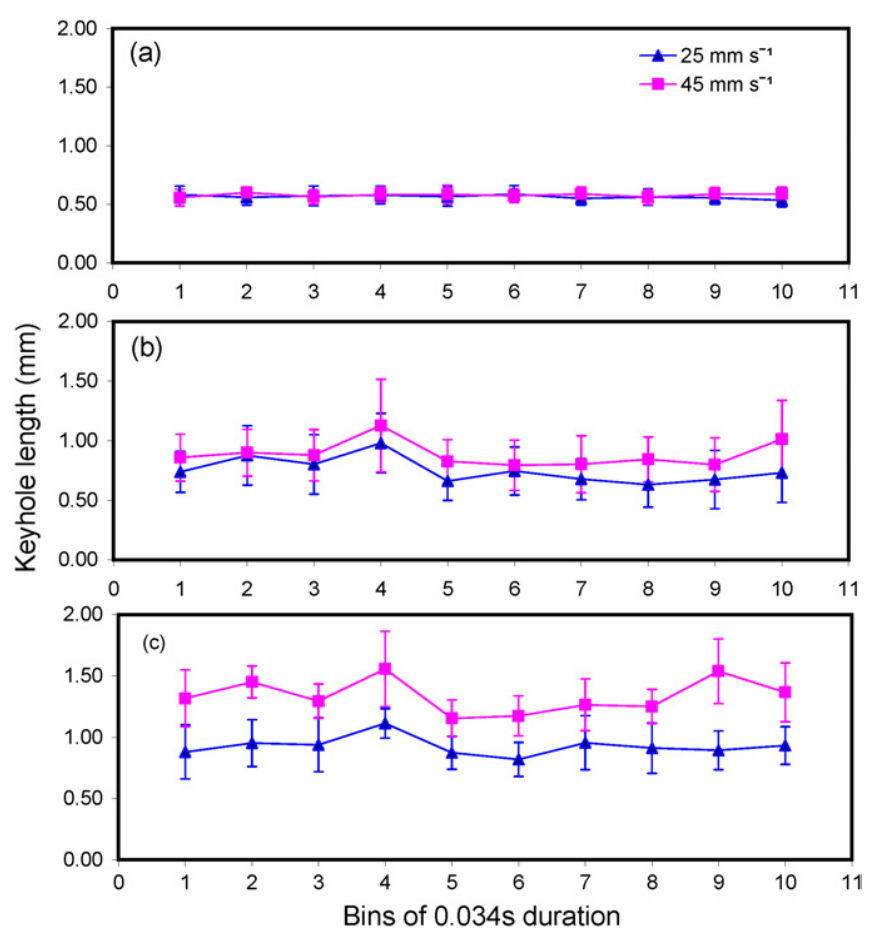

Figure 8. Evolution of average keyhole lengths for $(a)$ bare steel, (b) $7 \mu \mathrm{m}$ and (c) $20 \mu \mathrm{m}$ coating thickness GI coated steels, at welding speeds of 25 and $45 \mathrm{~mm} \mathrm{~s}^{-1}$.

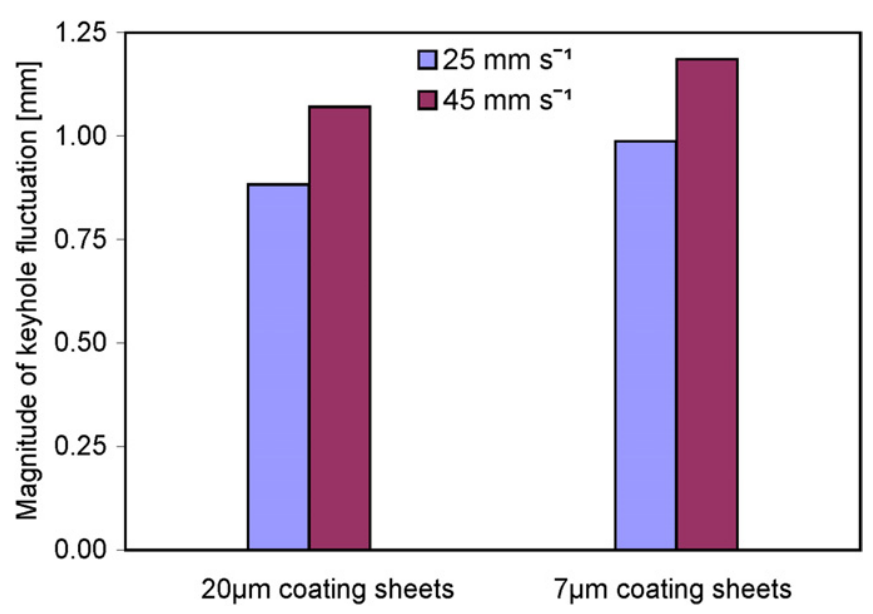

Figure 9. Mean keyhole fluctuation magnitude for coated sheets at welding speeds of 25 and $45 \mathrm{~mm} \mathrm{~s}^{-1}$.

keyhole. This explains the longer keyholes obtained when welding at higher speeds.

The standard deviations of measurements, shown as error bars in figure 8 , indicate the amplitude of the keyhole fluctuation. In contrast to the very stable keyhole behaviour obtained when welding bare steels, both coated materials show strong fluctuations as a result of weld pool eruption and induced melt pool oscillations. The mean fluctuation magnitude for both coated materials is shown in figure 9 . It is evident that the sheets with $20 \mu \mathrm{m}$ zinc coating thickness show slightly smaller oscillations than those with $7 \mu \mathrm{m}$ zinc coating thickness, independent of welding speed. It is also observed that the process is more stable when welding at the low speed. This is understandable because there is more time available for heat conduction and a larger zinc fusion zone can be produced at a lower welding speed. Such a zone is helpful because it reduces the effect of any sporadic change in the coating characteristics and consequently provides a more consistent supply of zinc vapour into the keyhole.

Although large fluctuation amplitudes are observed for both 20 and $7 \mu \mathrm{m}$ coating thickness materials, it is found that the data distributions in a $0.034 \mathrm{~s}$ time period are quite different. The examples given in figure 10 reveal two modes of keyhole fluctuation. In the case of the $20 \mu \mathrm{m}$ coating thickness (figure 10(a)), minimal fluctuations are observed and the keyhole mostly oscillates in a narrow range with occasional large excursions. This contrasts with the case of the thinner coating (figure 10(b)), where the keyhole continuously oscillates over a large amplitude.

\subsection{Analytical model of keyhole elongation}

In order to evacuate the vapour produced when welding steels with thicker coatings, a higher zinc vapour flow velocity will arise, and higher dynamic pressure therefore develops. The influence of zinc vapour evolution on keyhole elongation may be explained from an analysis of the pressure balance at the keyhole wall. For a stationary keyhole with a high aspect ratio, the following pressure balance is given by kroos et al [32,33]:

$$
p_{\mathrm{v}}+p_{\mathrm{i}}+p_{\mathrm{d}}=p_{\mathrm{s}}+p_{\gamma}
$$

where $p_{\mathrm{v}}$ is the vapour recoil pressure, $p_{\mathrm{i}}$ is the radiation pressure, $p_{\mathrm{d}}$ is the hydrodynamic pressure due to a melt flow, $p_{\mathrm{s}}$ is the hydrostatic pressure and $p_{\gamma}$ is the pressure due to surface tension. The right-hand terms try to close the keyhole whilst the left-hand terms have the opposite effect.

Calculations can be found in the literature to estimate the values of the above terms $[1,14,34]$. It appears that $p_{\mathrm{i}}$ and $p_{\mathrm{s}}$ are small compared with other terms and for the purpose of the present discussion can be neglected. The hydrodynamic pressure $p_{\mathrm{d}}$ is

$$
p_{\mathrm{d}}=\frac{1}{2} \rho\left(v_{\max }^{2}-v_{\min }^{2}\right),
$$

where $\rho$ is the liquid density and $v_{\max }$ and $v_{\min }$ are liquid flow velocities around the keyhole. The minimum velocity $v_{\min }$ is assumed to be the welding speed $v$ and the maximum velocity $v_{\text {max }}$ is calculated to be between 2 and 4 times the welding speed for welding speeds of 25 to $100 \mathrm{~mm} \mathrm{~s}^{-1}$ [22-24]. Hence this term is also negligibly small $(<0.5 \mathrm{kPa})$ at low to moderate welding speeds. For a cylindrical keyhole we can therefore write

$$
p_{\mathrm{v}} \approx p_{\gamma}
$$

as a good first order description of the pressure balance. The surface tension pressure term is

$$
p_{\gamma}=\frac{\gamma}{r}
$$

where $\gamma$ is the surface tension coefficient $\gamma=1.6 \mathrm{~N} \mathrm{~m}^{-1}$ (typical for the range of mean pool surface temperatures experienced) $[9,10,34]$ and $r$ is the average keyhole radius determined from camera images to be $\sim 0.26 \mathrm{~mm}$. The surface tension pressure $p_{\gamma}$ is therefore of the order $6.2 \mathrm{kPa}$. 

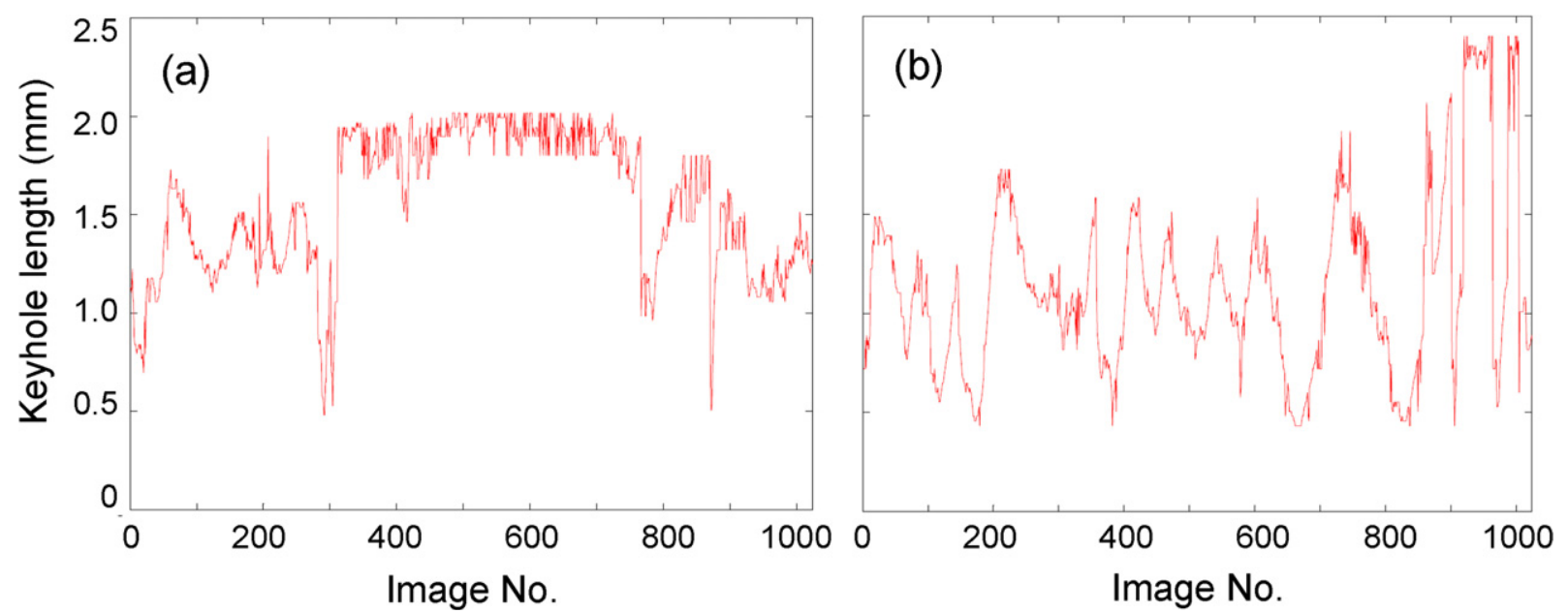

Figure 10. Data distributions in a bin (34 ms) for (a) $20 \mu \mathrm{m}$ and (b) $7 \mu \mathrm{m}$ coating thickness GI coated sheets (laser power: $3 \mathrm{~kW}$, welding speed is $45 \mathrm{~mm} \mathrm{~s}^{-1}$ ).

For the elongated keyhole, the keyhole rear wall is not significantly exposed to the laser beam due to the longer distance from the keyhole front wall, which explains the darker rear wall observed when welding zinc-coated steels (see figure 7). Based on geometrical considerations, radiation due to reflection from the keyhole front wall onto the rear wall may also be expected to be small, thus, there is little laser-induced vaporization on the rear wall and the effect of $p_{\mathrm{v}}$ is minor. The rear wall shape is mainly controlled by the surface tension of liquid metal, the hydrodynamic pressure due to the flow of molten steel and the zinc vapour pressure exerted on the rear keyhole wall. The zinc vapour impinges upon the rear keyhole wall restricting its forward motion. The resultant pressure $p_{\mathrm{z}}$ plays an important role in maintaining an elongated keyhole. Fabbro et al [7] employed a simplified description of a free jet emitted from a nozzle, to estimate the pressure $p_{\mathrm{z}}$ exerted on the keyhole rear wall $[35,36]$. The flow on the axis of the jet is

$$
p_{z}=p_{0} \cdot\left(\frac{X_{0}}{x}\right)^{2}, \quad x \geqslant X_{0},
$$

where $x$ is the distance along the axis of the jet from the exit of the nozzle (keyhole length here), $p_{0}$ is the reservoir pressure that feeds the jet and $X_{0}$ is a characteristic distance for the decrease in the velocity field of the emitted flow. An evaluation of $X_{0}$ for turbulent flow is given by the following empirical equation [7]

$$
X_{0}=\frac{3 D R e_{\mathrm{c}}}{16},
$$

where $D$ is a characteristic dimension of the nozzle exit, estimated here to be the total coating thickness at the interface, and $R e_{\mathrm{c}}$ is the critical Reynolds number characterizing the laminar to turbulent transition for free jet flows. A typical value for $R e_{\mathrm{c}}$ of 40 is given in the literature [35,36].

It has been reported by Fabbro et al [20] and Kamimuki et al [21] that a side gas jet applied from a leading position can lead to a rearward melt flow. It is therefore reasonable to expect a similar effect when a vapour flow is applied from the middle of the keyhole front wall. Dasgupta et al [37] have modelled the velocity field of the melt during laser welding of GI steel by considering the effect of zinc as an additional pressure. They show that the presence of zinc vapour increases liquid metal velocity by $30 \%$ when welding sheets with a $7 \mu \mathrm{m}$ coating thickness, with a laser power of $3 \mathrm{~kW}$ at a welding speed of $31 \mathrm{~mm} \mathrm{~s}^{-1}$. From the high speed images shown in figure 7 , it is observed that the melt pool at the sides of the keyhole becomes narrower when welding zinc-coated steels, thus flow with higher velocity is required to maintain the mass balance. Hence the hydrodynamic pressure term $p_{\mathrm{d}}$ needs to be taken into account. The magnitude of the hydrodynamic pressure, estimated based on the experimental observation of keyhole side walls, is given in table 2, which confirms that $p_{\mathrm{d}}$ increases with increasing coating thickness. The pressure balance equation for an elongated keyhole is therefore

$$
p_{\mathrm{d}}+p_{z}=p_{\gamma} .
$$

The surface tension term $p_{\gamma}$ is assumed to be constant and takes the same value calculated for the case of the cylindrical keyhole. This assumption is reasonable based on the observation that the radii of keyhole walls do not show significant differences when welding zinc-coated or non-coated steels (see figure 7). With known hydrodynamic pressure $p_{\mathrm{d}}$, the zinc vapour pressure exerted on the keyhole rear wall $p_{z}$ can be evaluated; $p_{z}$ decreases with increasing welding speed and coating thickness as shown in table 2 . The surface tension term $p_{\gamma}$ is a constant and the hydrodynamic pressure term $p_{\mathrm{d}}$ increases with the increasing welding speed or coating thickness, a decreasing $p_{\mathrm{z}}$ is therefore required to balance both sides of (7). In addition, $p_{\mathrm{z}}$ varies inversely as the square of the distance from the exit $x$ according to (5).

Combining (2), (5), (6) and (7), and replacing $v_{\min }$ by the welding speed $v$, results in the pressure balance

$$
\frac{1}{2} \rho\left(v_{\max }^{2}-v^{2}\right)+p_{0} \cdot\left(\frac{3 D R e_{c}}{16 x}\right)^{2}=p_{\gamma}
$$

The maximum velocity $v_{\max }$ is controlled by mass conservation. The metal melted at the keyhole front wall 
Table 2. Measured keyhole and weld pool properties and flow velocity and derived pressures for different welding speeds.

\begin{tabular}{|c|c|c|c|c|}
\hline Welding Speed & Keyhole/Pool Property & Bare steel & $7 \mu \mathrm{m}$ coated & $20 \mu \mathrm{m}$ coated \\
\hline $25 \mathrm{~mm} \mathrm{~s}^{-1}$ & $\begin{array}{l}L(\mathrm{~mm}) \\
w(\mathrm{~mm}) \\
b(\mathrm{~mm}) \\
v_{\max }\left(\mathrm{mm} \mathrm{s}^{-1}\right) \\
p_{\mathrm{d}}(\mathrm{Pa}) \\
p_{\mathrm{z}}(\mathrm{Pa})\end{array}$ & $\begin{array}{l}0.56( \pm 0.07) \\
0.53 \\
0.23 \\
53( \pm 4) \\
8 \\
\text { NA }\end{array}$ & $\begin{array}{l}0.72( \pm 0.18) \\
0.48 \\
0.15 \\
68( \pm 7) \\
14 \\
6.14 \times 10^{3}\end{array}$ & $\begin{array}{l}0.93( \pm 0.18) \\
0.51 \\
0.04 \\
175( \pm 18) \\
107 \\
6.05 \times 10^{3}\end{array}$ \\
\hline $35 \mathrm{~mm} \mathrm{~s}^{-1}$ & $\begin{array}{l}L(\mathrm{~mm}) \\
w(\mathrm{~mm}) \\
b(\mathrm{~mm}) \\
v_{\max }\left(\mathrm{mm} \mathrm{s}^{-1}\right) \\
p_{\mathrm{d}}(\mathrm{Pa}) \\
p_{\mathrm{z}}(\mathrm{Pa})\end{array}$ & $\begin{array}{l}0.57( \pm 0.06) \\
0.51 \\
0.21 \\
77( \pm 5) \\
17 \\
\text { NA }\end{array}$ & $\begin{array}{l}0.82( \pm 0.16) \\
0.52 \\
0.07 \\
138( \pm 19) \\
64 \\
6.09 \times 10^{3}\end{array}$ & $\begin{array}{l}1.17( \pm 0.20) \\
0.53 \\
0.03 \\
338( \pm 32) \\
404 \\
5.75 \times 10^{3}\end{array}$ \\
\hline $45 \mathrm{~mm} \mathrm{~s}^{-1}$ & $\begin{array}{l}L(\mathrm{~mm}) \\
w(\mathrm{~mm}) \\
b(\mathrm{~mm}) \\
v_{\max }\left(\mathrm{mm} \mathrm{s}^{-1}\right) \\
p_{\mathrm{d}}(\mathrm{Pa}) \\
p_{\mathrm{z}}(\mathrm{Pa})\end{array}$ & $\begin{array}{l}0.58( \pm 0.05) \\
0.52 \\
0.19 \\
106( \pm 9) \\
33 \\
\text { NA }\end{array}$ & $\begin{array}{l}0.91( \pm 0.20) \\
0.49 \\
0.08 \\
180( \pm 25) \\
108 \\
6.05 \times 10^{3}\end{array}$ & $\begin{array}{l}1.34( \pm 0.18) \\
0.48 \\
0.04 \\
332( \pm 35) \\
385 \\
5.77 \times 10^{3}\end{array}$ \\
\hline $55 \mathrm{~mm} \mathrm{~s}^{-1}$ & $\begin{array}{l}L(\mathrm{~mm}) \\
w(\mathrm{~mm}) \\
b(\mathrm{~mm}) \\
v_{\max }\left(\mathrm{mm} \mathrm{s}^{-1}\right) \\
p_{\mathrm{d}}(\mathrm{Pa}) \\
p_{\mathrm{z}}(\mathrm{Pa})\end{array}$ & $\begin{array}{l}0.59( \pm 0.06) \\
0.53 \\
0.16 \\
144( \pm 8) \\
63 \\
\text { NA }\end{array}$ & $\begin{array}{l}0.96( \pm 0.22) \\
0.53 \\
0.07 \\
223( \pm 15) \\
167 \\
5.99 \times 10^{3}\end{array}$ & $\begin{array}{l}1.42( \pm 0.24) \\
0.49 \\
0.04 \\
419( \pm 39) \\
617 \\
5.54 \times 10^{3}\end{array}$ \\
\hline
\end{tabular}

should be transported to the melt pool behind the keyhole. The mass of liquid steel melted per unit time is

$$
\dot{m}=(w+2 b) \cdot v \cdot 2 t_{\mathrm{p}} \cdot \rho,
$$

where $w$ is the keyhole width, $b$ is the width of liquid metal at the keyhole side wall (figure 10) and $t_{\mathrm{p}}$ is the sheet thickness. The values of $w$ and $b$ were measured from recorded images with a pixel resolution of $\pm 0.015 \mathrm{~mm}$, and are given in table 2 . The mass flow rate given by (9) must be balanced by the melt that flows around the keyhole (along the keyhole side walls), which is of the order $v_{\max } \cdot 2 b \cdot 2 t_{\mathrm{p}} \cdot \rho$, thus

$$
v_{\max }=\frac{w+2 b}{2 b} \cdot v
$$

The calculated $v_{\max }$ are given in table 2 . In the case of bare steel, the results obtained are in agreement with the published calculated values [22-24] (i.e. 2 to 3 times the welding speed). It is reasonable therefore to use this expression to estimate the flow speed when welding zinc-coated steels. It is shown in table 2 that when welding sheets with the thicker coating, a higher melt flow velocity on the keyhole side wall is obtained, leading to a higher hydrodynamic pressure as discussed.

A number of estimations for the reservoir pressure $p_{0}$ can be found in the literature $[2,7]$, ranging from the saturation pressure of zinc vapour at the steel melting temperature $(\sim 5 \mathrm{MPa})$ to the ferrostatic head $(\sim 50 \mathrm{~Pa})$. The reservoir pressure depends on the mass flow rate of zinc vapour given by

$$
\dot{m}_{\mathrm{z}}=A_{\mathrm{n}} \rho_{\mathrm{z}, \mathrm{v}} v_{\mathrm{v}}=A_{\mathrm{s}} \rho_{\mathrm{z}, \mathrm{s}} v
$$

where $A_{\mathrm{n}}$ is the nozzle (escape channel) area, $A_{\mathrm{s}}$ the area of the zinc vaporization front and subscripts $\mathrm{z}, \mathrm{v}$ and $\mathrm{s}$ refer to zinc and vapour and solid states, respectively. Equating the reservoir pressure to the (vapour) dynamic pressure yields

$$
p_{0}=\frac{1}{2} \rho_{\mathrm{z}, \mathrm{v}} v_{\mathrm{v}}^{2}=\frac{1}{2 \rho_{\mathrm{z}, \mathrm{v}}}\left(\frac{A_{\mathrm{s}} \rho_{\mathrm{z}, \mathrm{s}}}{A_{\mathrm{n}}}\right)^{2} v^{2} .
$$

Taking the first order assumption that the density of zinc vapour is proportional to the reservoir pressure; i.e. $\rho_{\mathrm{z}, \mathrm{v}}=$ $p_{0} \cdot \rho_{\mathrm{z}, \mathrm{v}}^{\circ} / p_{\text {atm }}$, then

$$
p_{0} \approx k_{1} v, \quad \text { where } k_{1}=\sqrt{\frac{p_{\mathrm{atm}}}{2}}\left(\frac{A_{\mathrm{s}} \rho_{\mathrm{z}, \mathrm{s}}}{A_{\mathrm{n} \sqrt{\rho_{\mathrm{z}, \mathrm{v}}^{o}}}}\right) .
$$

Here $v$ is the welding speed. $p_{\text {atm }}$ is the atmospheric pressure ( 1 bar), $A_{\mathrm{n}}$ is the area of the gap at the keyhole front wall for zinc vapour escape, $A_{\mathrm{s}}$ is the area of the zinc vaporization front. $\rho$ is the density and subscripts $\mathrm{z}, \mathrm{v}$ and $\mathrm{s}$ refer to zinc and vapour and solid states, respectively, and $\rho_{\mathrm{z}, \mathrm{v}}^{\circ}$ is the vapour density at standard pressure, which can be calculated using Clausius-Clapeyron equation.

The values of the variables involved in the equation are given in table $3 . A_{\mathrm{n}}$ and $A_{\mathrm{s}}$ are given by

$$
\begin{aligned}
& A_{\mathrm{n}}=\pi \cdot \frac{w}{2} \cdot 2 t_{\mathrm{c}} \\
& A_{\mathrm{s}}=\pi \cdot r_{\mathrm{v}} \cdot 2 t_{\mathrm{c}}
\end{aligned}
$$

where $w$ and $r_{\mathrm{v}}$ are defined in figure 11. The keyhole width $w$ is determined from the high speed images while $r_{\mathrm{v}}$ is determined by temperature measurements performed at the interface between two sheets, and $t_{\mathrm{c}}$ is the coating thickness. The values of the variables involved in the estimate of $k_{1}$ are given in table 3 . 
Table 3. Variables involved in the calculation of reservoir pressure equation (13).

\begin{tabular}{|c|c|c|c|c|c|c|c|c|}
\hline \multirow{3}{*}{$\begin{array}{l}\text { Welding speed }\left(\mathrm{mm} \mathrm{s}^{-1}\right) \\
w(\mathrm{~mm})\end{array}$} & \multicolumn{5}{|c|}{$7 \mu \mathrm{m}$ coated } & \multicolumn{3}{|c|}{$20 \mu \mathrm{m}$ coated } \\
\hline & 25 & 35 & 45 & 55 & 25 & 35 & 45 & 55 \\
\hline & $\begin{array}{l}\text { From } \mathrm{t} \\
\text { coating }\end{array}$ & $\begin{array}{l}\text { ble } 2 \mathrm{i} \\
\text { thickn }\end{array}$ & $\begin{array}{l}\text { can be } \\
\text { s. He }\end{array}$ & $\begin{array}{l}\text { een th } \\
\text { an av }\end{array}$ & $\begin{array}{l}w \text { is } \mathrm{i} \\
\text { age of }\end{array}$ & $\begin{array}{l}\text { sensiti } \\
.51 \mathrm{~m}\end{array}$ & $\begin{array}{l}\text { to we } \\
\text { is use }\end{array}$ & ding speed and \\
\hline$r_{\mathrm{v}}(\mathrm{mm})$ & 1.16 & 1.01 & 0.94 & 0.83 & 0.99 & 0.93 & 0.89 & 0.81 \\
\hline$A_{\mathrm{s}} / A_{\mathrm{n}}$ & 4.5 & 4.0 & 3.7 & 3.2 & 4.1 & 3.8 & 3.5 & 3.1 \\
\hline$\rho_{\mathrm{z}, \mathrm{s}}\left(\mathrm{kg} \mathrm{m}^{-3}\right)$ & \multicolumn{8}{|c|}{7140} \\
\hline$\rho_{z, v}^{\circ}\left(\mathrm{kg} \mathrm{m}^{-3}\right)$ & \multicolumn{8}{|c|}{1.8} \\
\hline$k_{1}\left(\mathrm{~N} \mathrm{~s} \mathrm{~m}^{-3}\right) \times 10^{6}$ & 5.4 & 4.7 & 4.4 & 3.9 & 4.6 & 4.3 & 4.2 & 3.8 \\
\hline$p_{0}(\mathrm{~Pa}) \times 10^{5}$ & 1.4 & 1.7 & 2.0 & 2.2 & 1.2 & 1.5 & 1.9 & 2.0 \\
\hline
\end{tabular}

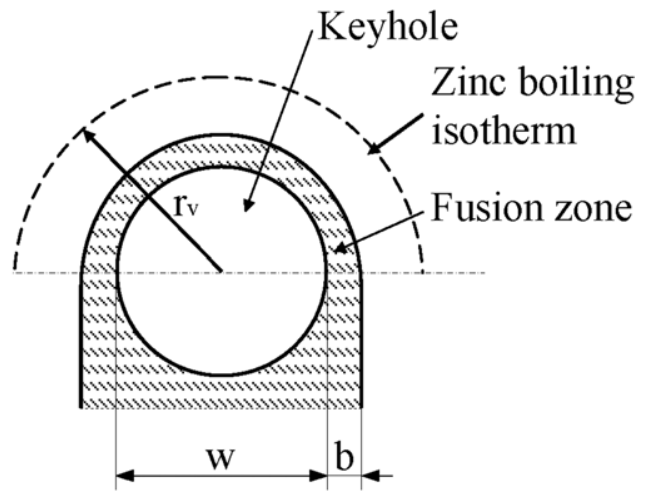

Figure 11. Definition of parameters $w, b$ and $r_{\mathrm{v}}$.

An accurate evaluation of $k_{1}$ requires accurate data of the thermal field surrounding the weld and measurements of both the keyhole and zinc vapour jet. The estimate shown in table 3 is approximate because the nozzle area $A_{\mathrm{n}}$ is affected by the reservoir pressure. When the pressure is less than the surface tension of the melt, this nozzle disappears. Hence, the actual nozzle area $A_{\mathrm{n}}$ in the case of $7 \mu \mathrm{m}$ coating thickness is smaller than the calculated value. This is also supported by the low appearance rate of the vapour escape channel when welding with a $7 \mu \mathrm{m}$ coating. According to equation (13), a decrease in $A_{\mathrm{n}}$ results in a larger $k_{1}$ and $p_{0}$. In contrast, for the case of the $20 \mu \mathrm{m}$ coating thickness, $A_{\mathrm{n}}$ can be larger than that calculated in table 3 because the vapour pressure makes a conically shaped nozzle as shown in figure 6 , leading to a reduction of $k_{1}$ and $p_{0}$. Welding speeds also influence $k_{1}$ by decreasing $A_{\mathrm{s}}$ with increasing welding speed. All these factors can result in some deviations from the estimation given in the table.

For simplicity, $k_{1}$ is treated as a constant of proportionality and chosen to match the measured values at a welding speed of $25 \mathrm{~mm} \mathrm{~s}^{-1}$. The experimentally derived values of $k_{1}$ and $p_{0}$ are given in table 4 . It can be seen that the values of $k_{1}$ shown in table 4 are generally of the same order as the calculated values shown in table 3 . In addition, the differences in $k_{1}$ for the different coating thicknesses are supported by examining the order of magnitude of the surface tension of the melt acting to close the channel on the keyhole front wall. This is calculated using (4), with a local surface tension coefficient of $1.4 \mathrm{~N} \mathrm{~m}^{-1}$ (at $3000 \mathrm{~K}$ ) [9] and radius of corresponding coating thickness, resulting in $7 \times 10^{4} \mathrm{~Pa}$ in the case of the $20 \mu \mathrm{m}$ coating thickness and $2 \times 10^{5} \mathrm{~Pa}$ in the case of $7 \mu \mathrm{m}$ coating thickness. The higher surface tension in the case of thinner
Table 4. Experimentally derived values of $k_{1}$ and $p_{0}$ obtained by matching the measured data at $25 \mathrm{~mm} \mathrm{~s}^{-1}$.

\begin{tabular}{lccccccccc}
\hline & \multicolumn{3}{c}{$7 \mu \mathrm{m}$ coated } & \multicolumn{4}{c}{$20 \mu \mathrm{m}$ coated } \\
\hline $\begin{array}{l}\text { Welding speed } \\
\left(\mathrm{mm} \mathrm{s}^{-1}\right)\end{array}$ & 25 & 35 & 45 & 55 & 25 & 35 & 45 & 55 \\
$k_{1}\left(\mathrm{~N} \mathrm{~s} \mathrm{~m}^{-3}\right) \times 10^{6}$ & \multicolumn{4}{c}{11.5} & & \multicolumn{4}{c}{2.3} \\
$p_{0}(\mathrm{~Pa}) \times 10^{5}$ & 2.8 & 4.0 & 5.1 & 6.3 & 0.6 & 0.8 & 1.1 & 1.3 \\
\hline
\end{tabular}

coating explains the higher reservoir pressure required to open the channel. In this case, the vapour evacuation channel appears less often, and elongation is not sustainable because the delivery of zinc vapour is not consistent due to the nonuniform coating, as shown in figure 2, resulting in significant keyhole fluctuations.

Despite these uncertainties, (13) may be employed together with (8) to determine the average keyhole length $x$, namely

$$
x=\frac{3 D R e_{\mathrm{c}}}{16} \cdot \sqrt{\frac{p_{0}}{p_{\gamma}-p_{\mathrm{d}}}}
$$

or

$$
x=\frac{3 D R e_{\mathrm{c}}}{16} \cdot \sqrt{\frac{k_{1} v}{p_{\gamma}-\frac{1}{2} \rho\left(v_{\max }^{2}-v^{2}\right)}} .
$$

The calculated keyhole lengths are compared with measured values in figure 12. Predictions from this simple analytical model are in good agreement with experimental measurements and the model provides an explanation for the major trends observed, including the elongation of the keyhole due to zinc vapour jetting (figure 7) and extension of keyhole length with increasing welding speed and coating thickness (figure 8). With increasing the coating thickness, both the characteristic dimension of the nozzle exit $D$ and hydrodynamic pressure $p_{\mathrm{d}}$ increase. These are consistent with the higher appearance rate of the zinc evacuation channel and the thinner side walls observed in the case of the $20 \mu \mathrm{m}$ coating thickness. However, a smaller reservoir pressure $p_{0}$ is obtained with the thicker coating, which can be explained by the different nozzle sizes and smaller surface tension of the melt film on the keyhole front wall. A combined effect of these factors leads to a longer keyhole as shown in figure 12. With increasing welding speeds, at a given coating thickness, $p_{0}$ and $p_{\mathrm{d}}$ increase according to (13) and (2), as more zinc vapour needs to escape through the keyhole per unit time through the same nozzle size and the melt velocity around the keyhole increases when welding at higher speeds. 


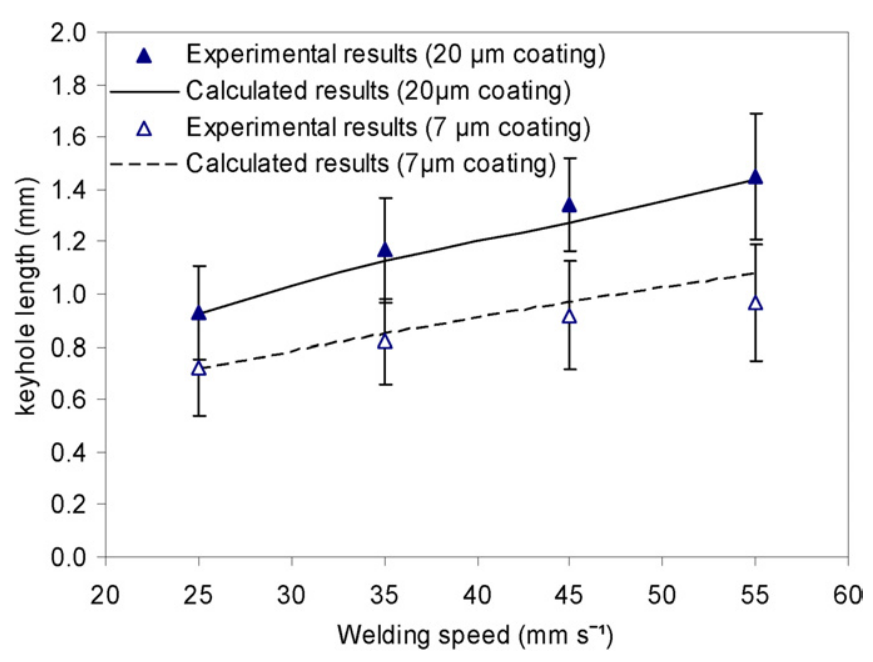

Figure 12. A comparison between the experimental and calculated values of keyhole lengths for welds made on GI zinc coated steels with $20 \mu \mathrm{m}$ and $7 \mu \mathrm{m}$ coating thicknesses. The error bars in figure represent the standard deviation of 10240 measurements of keyhole lengths made over a period of $0.34 \mathrm{~s}$.

\section{Conclusions}

We have shown that laser welding of steel sheets with a $20 \mu \mathrm{m}$ zinc coating thickness, in an overlap condition and without the introduction of a gap to vent the zinc vapour, can produce welds of acceptable quality. This surprising behaviour is linked to the development of an elongated keyhole with minimal positional fluctuations on the rear keyhole wall. The relatively high stability of the weld pool is ascribed to the consistent delivery of zinc vapour into the keyhole.

High speed coaxial visualization has shown that a zinc vapour evacuation channel is present on the keyhole front wall almost continuously during stable welding conditions and corresponding keyhole rear wall fluctuations are relatively small. Conversely, for sheets with a $7 \mu \mathrm{m}$ zinc coating thickness, the vapour is found to be inconsistently emitted into the keyhole and the keyhole rear wall is subject to persistent and severe fluctuations.

For both coating thicknesses, relatively stable keyhole behaviour is observed at low welding speed, which is believed to be a result of a larger zinc vaporization zone. More consistent zinc vapour generation can be expected and this in turn contributes to process stability and improved weld quality.

A simple analytical model has been developed to calculate the keyhole length and predictions show good agreement with experimental results, indicating that the dynamic pressure of the zinc vapour is responsible for elongation of the keyhole. A longer keyhole is obtained when welding sheets with thicker coatings or when welding at higher speeds.

\section{Acknowledgment}

This research was carried out under the project number MC8.05211 in the framework of the Research Program of the Materials Innovation Institute M2i (www.m2i.nl), the former Netherlands Institute for Metals Research.

\section{References}

[1] Graham M G, Hirak D M, Kerr H W and Weckman D C 1994 Nd-Yag laser welding of coated sheets steel J. Laser Appl. 6(4) 212-22

[2] Akhter R, Steen W M and Cruciani D 1998 Laser welding of zinc coated steel Proc. 5th Int. Conf. on Lasers in Manufacturing (Stuttgart, Germany, 1998) pp 195-206

[3] Bley H, Weyand L and Luft A 2007 An alternative approach for the cost-efficient laser welding of zinc-coated sheet metal CIRP Annu.-Manuf. Technol. 56 17-20

[4] Xie J and Denney P 2001 Galvanized steel joined with lasers Weld. J. 80 59-61

[5] Forrest M G and Feng L, Fundamental study of dual beam laser welding of zinc coated steel sheets in lap joint configuration with zero-gap 2003 Proc. 21st ICALEO (Jacksonville, MI) LMP Section E pp 356-460

[6] Pieters R R G M and Richardson I M 2005 Laser welding of zinc coated steel in overlap configuration with zero gap Sci. Technol. Weld. Joining 10 142-4

[7] Fabbro R, Coste F, Goebels D and Kielwasser M 2006 Study of CW Nd-Yag laser welding of $\mathrm{Zn}$-coated steel sheets J. Phys. D: Appl. Phys. 39 401-9

[8] Dasgupta A K and Mazumder J 2008 Laser welding of zinc coated steel: an alternative to resistance spot welding Sci. Technol. Weld. Joining 13 289-93

[9] Sahoo P, Debroy T and Mcnallan M J 1988 Surface tension of binary metal - surface active solute systems under conditions relevant to welding metallurgy Metall. Trans. B 19 483-91

[10] Wang Y, Shi Q and Li H 2001 Modeling of the effects of surface-active elements on flow patterns and weld penetration Metall. Mater. Trans B 32 145-61

[11] Matsunawa A, Kim J D, Seto N, Mizutani M and Katayama S 1998 Dynamics of keyhole and molten pool in laser welding J. Laser Appl. 10 247-54

[12] Klein T, Vicanek M and Simon G 1996 Forced oscillation of the keyhole in penetration laser beam welding $J$. Phys. D: Appl. Phys. 29 322-32

[13] Andrews J G and Atthey D R 1976 Hydrodynamic limit to penetration of a material by a high-power beam J. Phys. D: Appl. Phys. 9 2181-94

[14] Duley W W 1999 Laser Welding (New York: Wiley) pp 83-85

[15] Semak V and Matsunawa A 1997 The role of recoil pressure in energy balance during laser materials processing J. Phys. D: Appl. Phys. 30 2541-52

[16] Dowden J 2009 The Theory of Laser Materials Processing (Berlin: Springer)

[17] Kaul R, Ganesh P, Singh N, Jagdheesh R, Bhagat M S, Kumar H, Tiwari P, Vora H S and Nath A K 2007 Effect of active flux addition on laser welding of austenitic stainless steel Sci. Technol. Weld. Joining 12 127-37

[18] Mills K C, Keene B J, Brooks R F and Shirali A 1998 Marangoni effect in welding Marangoni and Interfacial Phenomena in Materials Processing (15 April 1998) (Phil. Trans.: Math., Phys. Eng. Sci. 356, No. 1739, pp 911-25)

[19] Lampa C, Kaplan A F H, Powell J and Magnusson C 1997 An analytical thermodynamic model of laser welding $J$. Phys. D: Appl. Phys. 30 1293-9

[20] Fabbro R, Slimani S, Doudet T, Coste F and Briand F 2006 Experimental study of the dynamical coupling between the induced vapour plume and the melt pool for Nd-Yag CW laser welding J. Phys. D: Appl. Phys. 39 394-400

[21] Kamimuki K, Inoue T, Yasuda K, Muro M, Nakabayashi T and Matsunawa A 2002 Prevention of welding defect by side gas jet flow and its monitoring method in continues wave Nd : YAG laser welding, J. Laser Appl. 14 136-45 
[22] Beck M, Berger P, Dausinger F and Hugel H 1991 Aspects of keyhole/melt interaction in high speed laser welding Proc. SPIE-Int. Soc. Opt. Eng. Part 2

1397 769-74

[23] Kaplan A 1994 Modellrechnung des laser-Tiefschweißens PhD Thesis Vienna University of Technology, Vienna, Austria

[24] Lampa C, Kaplan A, Resch M and Magnusson C 1998 Fluid flow and resolidification in deep penetration laser welding Lasers Eng. 7 243-51

[25] Mazumder J, Mohanty P S and kar A 1996 Mathematical modelling of laser materials processing Int. J. Mater. Product Technol. 11 193-252

[26] Pieters R R G M, Thiessen R and Richardson I M 2003 Laser welding of zinc coated steel in an overlap configuration IIW2003 Conf. (Bucharest, Romania 2003) IIW Doc. IV-1605-03-Z

[27] Pieters R R G M, Goos C, Rietman B and Richardson I M 2006 Zinc transport phenomena in laser welding of coated sheet steel in overlap configuration IIW2006 Conf. (Quebec, Canada, 2006) IIW Doc. IV-1896-08

[28] Geiger M, Leitz K H and Koch H 2009 A 3D transient model of keyhole and melt pool dynamics in laser beam welding applied to the joining of zinc coated sheets Prod. Eng. Res. Dev. 3 127-36
[29] Schmidt M, Otto A and Kageler C 2008 Analysis of Yag laser lap-welding of zinc coated steel sheets $C I R P$ Annu.-Manuf. Technol. 57 213-6

[30] Fabbro R, Slimani S, Coste F and Briand F 2005 Study of keyhole behaviour for full penetration Nd-YAG CW laser welding J. Phys. D: Appl. Phys. 38 1881-7

[31] Krasnoperov M Y, Pieters R P G M and Richardson I M 2004 Weld pool geometry during keyhole laser welding of thin steel sheets Sci. Technol. Weld. Joining 9 501-6

[32] Kroos J, Geatzke U and Simon G 1993 Towards a self-consistent model of the keyhole in penetration keyhole beam welding J. Phys. D: Appl. Phys. 26 474-80

[33] Kroos J, Geatzke U, Vicanek M and Simon G 1993 Dynamic behaviour of the keyhole in laser welding J. Phys. D: Appl. Phys. 26 481-6

[34] Aalderink B J, de Lange D F, Arts R and Meijer J 2007 Keyhole shapes during laser welding of thin metal sheets J. Phys. D: Appl. Phys. 40 5388-93

[35] Schlichting H 1982 Grenzchicht Theorie (Karlsruhe: Braun)

[36] Abramovich G N 1963 The Theory of Turbulent Jets (Cambridge, MA: MIT Press)

[37] Dasgupta A K, Mazumder J and Li P 2007 Physics of zinc vaporization and plasma absorption during $\mathrm{CO}_{2}$ laser welding J. Appl. Phys. 102053108 